\title{
ENTERIC FEVER IN TRAVELERS: AN UPDATED INSIGHT
}

\author{
VARSHIL MEHTA*
}

MGM Medical College, Navi Mumbai, Maharashtra, India. Email: varshil91@gmail.com

Received: 08 August 2016, Revised and Accepted: 15 August 2016

\begin{abstract}
Enteric fever is a broad term used to represent typhoid and paratyphoid fever which is caused by S. typhi and S. paratyphi respectively. The most common cause being S. typhi, overall. However, S. paratyphi is known to infect the travelers at a higher rate. Indian subcontinent being one of the most endemic region, it is always beneficial for the travelers to get immunized while traveling to these areas. However, Vaccination to S. paratyphi is not yet available, hence travelers often fall prey to the disease. The morbidity is often high but mortality is very rare, especially due to first line treatment drugs like ceftriaxone, nalidixic acid and floroquinolones (if patients are sensitive to it). Recently, it was observed that Multi-drug resistance (Resistance to at least ampicillin, chloramphenicol and trimethoprim-sulfamethoxazole]) was limited to Typhi isolates and was increased at an exponential rate. Hence, with increasing resistance to these drugs, developing vaccines or new drugs against these bacteria, remains an area of prime interest.
\end{abstract}

Keywords: Salmonella typhi, Salmonella paratyphi, Enteric fever, Traveler.

(C) 2016 The Authors. Published by Innovare Academic Sciences Pvt Ltd. This is an open access article under the CC BY license (http://creativecommons. org/licenses/by/4. 0/) DOI: http://dx.doi.org/10.22159/ajpcr.2016.v9s3.14543

\section{INTRODUCTION}

Enteric (typhoid or paratyphoid) fever is a systemic illness caused by Salmonella enterica serotype Typhi or S. enterica serotype Paratyphi. Salmonella typhi and S. paratyphi are highly adapted to humans and have no nonhuman animal or environmental reservoirs. Enteric fever is acquired by ingestion of fecally contaminated food and water Continued excretion of a large number of bacteria by asymptomatic carriers or individual who have recently recovered from enteric fever is a common and is a major source of spread from an epidemic. In areas of endemicity, enteric fever is associated with drinking, contamination water, eating food prepared outside the home, having a close relative with enteric fever and poor housing. A recent study of Indonesia identified consumption of food from street vendors and flooding as being independently associated with paratyphoid fever [1]. In contrast, typhoid fever was associated with the household risk factor such as a presence of a household member with recent typhoid fever, lack of soap for hand washing, and sharing food from the same plate.

\section{PATHOGENESIS}

Genus Salmonella consists of Gram-negative bacilli that parasitize the intestinal tract of infected human beings. It was first observed by Eberth (1880) and was isolated by Gaffky (1884), so it also called Eberth-Gaffky bacillus. The most common cause of enteric fever is Salmonella typhi, hence the frequent use of the name typhoid fever. However, the similar clinical syndrome is also caused by $S$. paratyph $\mathrm{A}, \mathrm{B}$ and $\mathrm{C}$. Thus, enteric fever is the more inclusive term. Reports from endemic countries demonstrate that $S$. typhi is the dominant pathogen, accounting for approximately $80 \%$ cases. In a report from Nepal, the ratio of $S$. paratyphi to $S$. typhi was $70 \%$ versus $30 \%$ among travelers, while this ratio was reversed as expected in the local population [2].

All pathogenic species of Salmonella, when arrive in the gut are engulfed by phagocytic cells, which then present them to the macrophages in the lamina propria after passing through the mucosa. Non-typhoidal salmonellae are phagocytized throughout the distal ileum and colon. With toll-like receptor (TLR)-5 and TLR-4/MD2/CD-14 complex, macrophages recognize pathogen-associated molecular patterns (PAMPs) such as lipopolysaccharides and flagella. Macrophages and intestinal epithelial cells then attract $\mathrm{T}$ cells and neutrophils which secrete interleukin 8, causing inflammation and suppressing the infection $[3,4]$.

In contrast to the non-typhoidal salmonellae, S. typhi and Paratyphi enter the host's system primarily through the distal part of ileum. They have specialized fimbriae that adhere to the epithelium over lymphoid tissue in the ileum (Peyer patches), the main relay point for macrophages traveling from the gut into the lymphatic system. The bacteria then induce their host macrophages to attract more and more macrophages [4].

S. typhi has a virulence (Vi) capsular antigen which masks PAMPs, avoiding neutrophil-based inflammation, while the most common Paratyphi like Paratyphi A, does not. This may explain the greater infectivity of typhi compared with the most of its other subtypes [5].

Typhoidal Salmonella uses the macrophages' cellular machinery for their own reproduction [6] as they are carried from the mesenteric lymph nodes to the thoracic duct and the lymphatics and then through to the reticuloendothelial tissues of the liver, spleen, bone marrow, and lymph nodes. Once there, they pause and continue to multiply until some critical density is reached. Afterward, the bacteria induce macrophage apoptosis, breaking out into the bloodstream to invade the entire body [3].

The bacteria then infect the gallbladder via either blood route or direct extension of infected bile. The result is that the organism re-enters the gastrointestinal tract in the bile and re-infects the Peyer patches. Bacteria that do not re-infect the host are typically shed in the stool and are then available to infect other hosts $[3,7]$.

\section{EPIDEMIC FACTORS}

Globally, each year, typhoid and paratyphoid fever, cause an estimated 26 million and 5 million illnesses respectively [8]. The mortality is estimated at 2,15,000 annually [9]. The most cases are confined to the developing world, where the disease is endemic with the greatest burden being in the Indian subcontinent and South East Asia. In developing countries, enteric fever is a sporadic disease that occurs mainly in returned travelers. Overall, it has been estimated that the incidence of typhoid among traveler to developing countries is 3-30 cases from 1,00,000 travelers [10]. The risk for traveler appears 
to vary by geographic region visited. Several reports indicate that the Indian subcontinent has the higher risk of acquiring typhoid fever. A recent travel was reported by $74 \%$ of patient with typhoid fever reported to the United States Centre for Disease Control and prevention between 1994 and 1999 [11]. More than one-half of these patients had traveled to India subcontinent (Afghanistan, Bangladesh, Bhutan, India, Pakistan, Nepal, and Sri-Lanka), 17\% travel to Mexico, $8 \%$ to the Philippines and $5 \%$ had to Haiti. The overall risk of typhoid fever from travel to the Indian subcontinent is 18 times higher than from any other geographic area [12]. In another data, the attack rate of travel to Mexico is $2 / 1,00,000$ journeys versus $10 / 1,00,000$ to the Indian subcontinent [13]. In a British report, $75 \%$ cases of typhoid fever were in travelers and the authors, estimation of global risk of typhoid fever, i.e., the risk of contracting typhoid fever when travelling to all other developing countries besides the Indian subcontinent was $1 / 1,00,000$ visits, compared with 30 per $1,00,000$ visits travel to the Indian subcontinent [14]. In 2013, 1,61,000 deaths occurred - down from 1,81,000 in 1990 [15]. Since few decades, the number of enteric fever cases acquired during international travel has substantially increased in the United States [12,16-18] and in other industrialized countries [19-22]. In one of the recent study conducted from 2008$2012,86 \%$ of typhoid cases were travel-associated [23], compared with 79\% during 1999 through 2006 [18]. The travel-associated percentage was even higher (91\%) for paratyphoid fever [23].

\section{RISK FACTORS FOR TRAVELERS}

Risk factors for contracting enteric fever have been assessed by several authors. As expected, travel to rural areas with poor sanitation was associated with a higher risk. Not following food and water precautions and not receiving pre-travel consultation increased the risk 10 times [24]. A German study found an increased risk among older travelers with a longer duration of stay (58 days vs. 19 days) [25]. In addition to more travel to rural areas, travelers visiting friends and relatives are less likely to have received pre-travel advice, less likely to food and water precautions and perhaps most importantly, by and large, do not perceive their risk or receive typhoid vaccine before travel.

\section{CLINICAL MANIFESTATIONS}

The clinical manifestation and severity of typhoid fever vary with the patient population studied. The most reports and textbook description related to study of a patient in endemic countries. Descriptions of the clinical presentation in travelers are scarce but an important difference in clinical manifestations exists between travelers to developing countries and local residents. These differences related to the likelihood of exposure to infection, age, and intensity of exposure, and may be affected by more rapid and readily available access to medical care. Most people with enteric fever present with a nonspecific febrile illness, often with an insidious onset, after an incubation period of 7-14 days (range 3-60 days). A headache, malaise, myalgia, and dry cough are common and the spleen enlarges. Arthralgia is less common for typhoid and paratyphoid fever than for rickettsial illness. The slowly increasing fever in a "stepladder" pattern is uncommon, although fever does not tend to worsen as the disease progresses. Often times, there are sudden episodes of shaking chills and rigor that resemble symptoms of fever due to malaria. Constipation and relatively bradycardia are common but necessary for the diagnosis. Rose spot (2-3 mm pink-red on the chest and abdomen) may appear, are often unnoticed, are often more prominent in cases of paratyphoid fever. The complication occurs in $10-15 \%$ of patients and probably are more common in patients who have ill for $>2$ weeks [26]. Gastrointestinal bleeding, intestinal perforation, and typhoid encephalopathy are the important complications. Travelers usually seek advice more promptly than do local patients, thus these complications are usually less common in the traveler population. Relapse occurs in $5-10 \%$ of patients, usually 2-3 weeks after the resolution of fever [3]. Relapses are typically milder than the original attack and the bacterial isolate from the relapse usually and has the same antibiotic susceptibility pattern as the original isolate. Importantly, 1-5\% of patients with enteric fever long term, asymptomatic carriers who may shed $S$. typhi in either urine or stool for $>1$ year [26]. Chronic carriage rates are higher among women's and among persons with biliary abnormalities such as gallstone. The chronic biliary carriage may occur in $2-5 \%$ of cases, even after treatment. The biliary carriage is defined as continued shedding of the organism for more than a year and is a public health risk, especially for infected individuals who work in the food industry.

The differential diagnosis in a traveler with suspected enteric fever is bored. Other considerations for patients returning from areas of endemicity with an undifferentiated febrile illness include malaria, rickettsial diseases (including murine and scrubs typhus), leptospirosis, dengue, hepatitis, and amebic liver abscess.

\section{LABORATORY INVESTIGATIONS}

The clinical diagnosis of enteric fever can be difficult because of nonspecific nature of symptoms and sign. A travel history to the Indian subcontinent or other areas of endemicity in a febrile patient should alert the physician to the possibilities of enteric fever. In a patient with enteric fever, the peripheral WBC count is usually normal to low and mild hepatic involvement may be reflected in slightly abnormal liver function test results. The definitive diagnosis of enteric fever requires the isolation of $S$. typhi and S. paratyphi from a specimen of blood, bone marrow or another extraintestinal site. Blood cultures are the standard diagnostic method, and the result can be positive in $60-80 \%$ in the $1^{\text {st }}$ week of fever. Blood culture is approximately $70 \%$ positive in the $2^{\text {nd }}$ week and it is negative on treatment with antibiotics. Feces cultures are almost as valuable as blood culture in the diagnosis of enteric fever. Urine culture is less useful than the culture of blood and feces; culture is generally positive in a second and the $3^{\text {rd }}$ week and then only in $25 \%$ of cases. Bone marrow culture is valuable as it is positive in most cases even when blood cultures are negative. The culture of bile obtained by duodenal aspiration is usually positive and may be employed for the detection of carriers.

Several serological tests have been developed to detect $S$. typhi antibodies. The role of the Widal test is controversial with divergent views on the tests utility in various areas of endemicity. Newer rapid S. typhi antibody test (IgM and IgG) may be useful in areas where enteric fever is endemic and resources are limited [27]. A multiplex PCR (mPCR) assay was recently developed for the detection of multiple Salmonella serotypes in different kind of food products. This technique can be used regularly for the rapid detection of Salmonella species in the food materials even at low levels of contamination [28]. However, no current serological test is sufficiently sensitive or specific to replaced culture based tests for the diagnosis of enteric fever.

\section{PREVENTION IN TRAVELERS}

Hygiene, food and water precautions are a more important, especially for prevention of paratyphoid fever, as there is no vaccine available for this. Vaccinations further reduce the risk of typhoid fever in visitors to endemic areas but provide incomplete protection [25]. However, in a recent survey done in 2009-2011, it was noted that less than $50 \%$ of the patients were only vaccinated against typhoid [30]. Data on the effectiveness of typhoid vaccine in travelers are sparse, as the population has not been studied sufficiently [30]. It is especially important to give appropriate preventive information to travelers visiting friends and relatives where possible.

\section{TREATMENT AND DRUG RESISTANCE}

Historically, typhoid fever was treated with chloramphenicol, ampicillin, and co-trimoxazole. In 1972, chloramphenicol resistance becomes widespread and since 1989, resistance to all three has been noted in strains in India, China, and Pakistan [32]. Resistance appears to be plasmid mediated, allowing the simultaneous acquisition of resistance to multiple drugs and the emergency of multidrug resistance strains. $50-80 \%$ of isolates from China and the Indian subcontinent are now 
multidrug resistance [33] and 93\% of the isolates in an outbreak in Tajikistan were multidrug resistance [34].

The introduction to fluoroquinolones was a major advance. The drugs were found to be highly effective, well-tolerated and could be administrated orally. Antibiotic such as ciprofloxacin quickly became the first-line agent. The treatment was also reduced from 14 days to as short as 5 days duration [35]. However, the increasing incidence of quinolones resistance is limiting the use of the class of the antibiotics. Ceftriaxone and other third-generation cephalosporins are a good choice of empirical therapy for travelers with suspected typhoid fever. An oral third-generation drug, cefixime has also been studied and found to be effective [3]. Drug resistance highlights an emerging crisis in the antibiotic treatment of enteric fever. Multidrug-resistant strains require expensive therapies that are less effective and result in higher stool carriage rates with a greater transmission potential, posing a publichealth risk, especially in countries where typhoid fever is endemic and by extension in travelers to these countries. One of the main reasons for the main emergency of fluoroquinolones resistant $S$. typhi and $S$. paratyphi in Asia is the widespread availability of relatively cheap, generic fluoroquinolones that can be purchased without a prescription. Azithromycin, which can be given orally, has shown promise in limited numbers of trials [36], with fever clearance times of 4-6 days and with rates of relapse and convalescent phase fecal carriage of $<3 \%$. Aztreonam and imipenem are expensive potential third-line drugs. Oral azithromycin was recently found to perform significantly better than ceftriaxone for the treatment of typhoid fever [37].

Despite demonstrating in vitro killing of salmonellae, first and second generation cephalosporins and an aminoglycoside are ineffective in treating enteric fever. A report of $113 \mathrm{~S}$. typhi strains collected from India from 1987 to 2006, demonstrated possible "MIC creep" for ceftriaxone, though no frank resistance was observed. A gradual increase in ceftriaxone MIC has been observed in last 5-years increments: $0.047 \mathrm{mcg} / \mathrm{ml}, 0.098 \mathrm{mcg} / \mathrm{ml}, 0.211 \mathrm{mcg} / \mathrm{ml}$, and $0.365 \mathrm{mcg} / \mathrm{mL}$ for ceftriaxone MIC [38]. Gentamicin is widely used as therapy for Gram-negative sepsis. However, it is important to note that this antibiotic is not used empirically to treat Gram-negative bacteremia in patients who have recently been visiting areas where enteric fever is endemic.

Eradication of the chronic carrier state is important to stop the spread of the disease and can be achieved in $>80 \%$ of cases with high dose ampicillin/amoxicillin with probenecid for 3 months or with ciprofloxacin for at least 4 weeks [26].

\section{THE ADVENT OF TYPHOID VACCINES}

The complex nature of the pathogenesis of $S$. typhi clinical infection has spurred the development of two primary types of vaccines. The parenteral vaccine takes advantage of the protective role of the circulating antibody response and lives attenuated oral vaccine rely on vigorous secretory IgA response and cell-mediated immunity to eliminate intracellular bacilli. Both vaccines are safe and well tolerated.

The live oral vaccine is an attenuated $S$. typhi strain, Ty21a which is mutual of Ty2 with a uridine diphosphogalactose 4-epimerase defect. The strain lacks the $\mathrm{Vi}$ antigen and is thus avirulent but contains immunogenic cell wall polysaccharides. Primary vaccination consists of one enteric coated capsule or lyophilized sachet on alternate days for 3-4 doses. The live attenuated vaccine is theoretically contraindicated in pregnancy and in those with cell-mediated immunosuppression. In addition, the concurrent use of antibiotics and antimalarials may interfere with the antibody response. The vaccines need to be refrigerated, cannot to be given children under 6 years of age and relies on the traveler compliance and memory to complete the three to four required doses [39].

The Vi antigen is a capsular polysaccharide antigen that allows $S$. typhi to survive in the blood leading to septicemia. The parenteral Vi vaccine

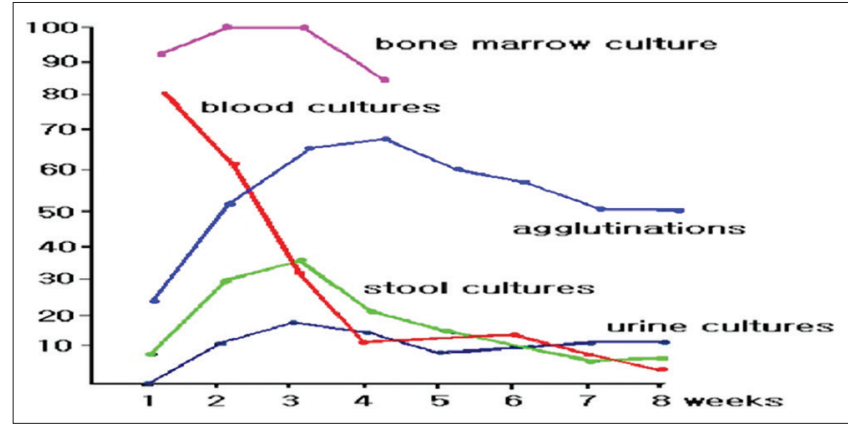

Graph 1: Laboratory diagnosis of typhoid fever. The approximate percentage of tests found positive during different stages of the disease (week 1-8)[29]

contains only the purified antigen and produces seroconversion following one dose. The vaccine is safe to be co-administered with other travel vaccines as well as antimalarials with no diminution in antibody response. However, because it is a polysaccharide, there is no boosting effect from revaccination and the duration of protection appears to be 2-3 years. Both the US Centre for Disease Control and Prevention and World Health Organization recommended typhoid vaccination for a person traveling to countries where enteric fever is endemic. These vaccines needed to be given at least 2 weeks before departure. Unfortunately, at present, there is no commercially available vaccine for the child travelers age $<2$ years.

\section{Precautions which needed to be taken}

The recent notification of $S$. typhi as a potential weapon of bioterrorism has helped to rekindle interest in important precautionary measures to help avoid infection with this organism. When traveling to the area of endemicity, travelers have to make sure that drinking water is boiled or properly bottled. Food should thoroughly cook preferably steaming hot when served. Fresh vegetables and fruits that have been washed in unclean water may be a source of infection. Breast-feeding of infants may need to be encouraged during travel to the area of endemicity. Clearly, eating food from street vendors is a risk for enteric fever, especially for enteric fever due to $S$. paratyphi A [1]. Finally, travelers visiting friends and relatives, especially those going to the Indian subcontinent need to be targeted for the prevention of enteric fever.

\section{Prospective Treatment Options}

An essential oil from Galangal (Alpinia galanga (Linn.) Pierre.) at a dose of $25 \mathrm{mg} / \mathrm{ml}, 50 \mathrm{mg} / \mathrm{ml}$ and $75 \mathrm{mg} / \mathrm{ml}$ was found to reduce the salmonella bacterial load in rats [40]. It was also observed that when antibiotics were attached with nanoparticles synthesized from Trametes sp. were found to be more effective against Salmonella species [41]. Also, methanolic extract of gyrocarpus asiaticus willd showed an effect in reducing the salmonella species [42]. A combination of plant extracts which includes Allium sativum (Amaryllidaceae), Szygium aromaticum (Myrtaceae), Berberis aristata (berberidace), Rhus cotinus (Anacardiaceae) and phyllanthus emblica (Phyllanthaceae) also showed a positive effect in restricting Salmonella species [43].

\section{CONCLUSION}

Two features characterize enteric fever in industrialized countries. One is the general decline in the incidence of the disease, and the second is the concomitant rise in the percentage of travel related enteric fever. Most of the cases are acquired in the Indian subcontinent where multidrug resistance is the norm and where the fluoroquinolone resistance is on the rise. Vaccine efficacy is generally tested in endemic areas, which rises questions of how the result correlate with those in naive travelers and what contribution those already immune make to the trial result. The current vaccine offers only moderate protection against $S$. typhi and no protection against $S$. paratyphi, which has become dominant pathogen among travelers. Thus, there is a great 
need for a combined vaccine, particularly with increasing antibiotic resistance in both $S$. typhi and S. paratyphi.

\section{REFERENCES}

1. Vollaard AM, Ali S, van Asten HA, Widjaja S, Visser LG, Surjadi C, et al. Risk factors for typhoid and paratyphoid fever in Jakarta, Indonesia. JAMA 2004;291(21):2607-15.

2. Schwartz E, Shlim DR, Eaton M, Jenks N, Houston R. The effect of oral and parenteral typhoid vaccination on the rate of infection with Salmonella typhi and Salmonella paratyphi A among foreigners in Nepal. Arch Intern Med 1990;150(2):349-51.

3. Parry CM, Hien TT, Dougan G, White NJ, Farrar JJ. Typhoid fever N Engl J Med 2002;347(22):1770-82.

4. Raffatellu M, Chessa D, Wilson RP, Tükel C, Akçelik M, Bäumler AJ. Capsule-mediated immune evasion: A new hypothesis explaining aspects of typhoid fever pathogenesis. Infect Immun 2006;74(1):19-27.

5. de Jong HK, Parry CM, van der Poll T, Wiersinga WJ. Hostpathogen interaction in invasive Salmonellosis. PLoS Pathog 2012;8(10):e1002933.

6. Ramsden AE, Mota LJ, Münter S, Shorte SL, Holden DW. The SPI-2 type III secretion system restricts motility of Salmonella-containing vacuoles. Cell Microbiol 2007;9(10):2517-29.

7. Christie AB. Infectious Diseases: Epidemiology and Clinical Practice. $4^{\text {th }}$ ed. Edinburgh, Scotland: Churchill Livingstone; 1987.

8. Buckle GC, Walker CL, Black RE. Typhoid fever and paratyphoid fever: Systematic review to estimate global morbidity and mortality for 2010. Journal of global health. 2012;2(1):10401.

9. Mortality GBD, Causes of Death C. Global, regional, and national age-sex specific all-cause and causespecific mortality for 240 causes of death, 1990-2013: a systematic analysis for the Global Burden of Disease Study 2013. The Lancet.385(9963):117-71.

10. Steffen R, Rickenbach M, Wilhelm U, Helminger A, Schär M Health problems after travel to developing countries. J Infect Dis 1987;156(1):84-91

11. Steinberg EB, Bishop R, Haber P, Dempsey AF, Hoekstra RM, Nelson JM, et al. Typhoid fever in travellers: Who should be targeted for prevention? Clin Infect Dis 2004;39(2):186-91.

12. Mermin JH, Townes JM, Gerber M, Dolan N, Mintz ED, Tauxe RV. Typhoid fever in the United States, 1985-1994: Changing risks of international travel and increasing antimicrobial resistance. Arch Intern Med 1998;158(6):633-8.

13. Ryan CA, Hargrett-Bean NT, Blake PA. Salmonella typhi infections in the United States, 1975-1984: Increasing role of foreign travel. Rev Infect Dis 1989;11:1-8.

14. Behrens R, Carroll B. The 10-Year trend of travel-associated infections imported into the UK. $7^{\text {th }}$ Conference of the International Society of Travel Medicine; Innsbruck, Austria; May 27-31; 2001.

15. GBD 2013 Mortality and Causes of Death, Collaborators. Global, regional, and national age-sex specific all-cause and causespecific mortality for 240 causes of death, 1990-2013: A systematic analysis for the Global Burden of Disease Study 2013. Lancet 2015;385(9963):117-71.

16. Gupta SK, Medalla F, Omondi MW, et al. Laboratory-based surveillance of paratyphoid fever in the United States: Travel and antimicrobial resistance. Clinical infectious diseases: An official publication of the Infectious Diseases Society of America. 2008;46(11):1656-63.

17. Ackers ML, Puhr ND, Tauxe RV, Mintz ED. Laboratory-based surveillance of Salmonella serotype Typhi infections in the United States: antimicrobial resistance on the rise. JAMA : the journal of the American Medical Association. 2000;283(20):2668-73.

18. Lynch MF, Blanton EM, Bulens S, et al. Typhoid fever in the United States, 1999-2006. JAMA: The journal of the American Medical Association. 2009;302(8):859-65.

19. Reddy S, Rangaiah J, Addiman S, Wareham D, Wilson P, Sefton A. Epidemiology, antibiotic resistance trends and the cost of enteric fever in East London, 2005-2010. Travel medicine and infectious disease. 2011;9(4):206-12.

20. Ty AU, Ang GY, Ang LW, James L, Goh KT. Changing epidemiology of enteric fevers in Singapore. Annals of the Academy of Medicine, Singapore. 2010;39(12):889-88.

21. Clark TW, Daneshvar C, Pareek M, Perera N, Stephenson I. Enteric fever in a UK regional infectious diseases unit: A 10 year retrospective review. The Journal of infection. 2010;60(2):91-98.

22. Keller A, Frey M, Schmid H, Steffen R, Walker T, Schlagenhauf P. Imported typhoid fever in Switzerland, 1993 to 2004. Journal of travel medicine. 2008;15(4):248-251.

23. Date KA, Newton AE, Medalla F, Blackstock A, Richardson L, McCullough A, Mahon, BE. (2016). Changing Patterns in Enteric Fever Incidence and Increasing Antibiotic Resistance of Enteric Fever Isolates in the United States, 2008-2012. Clinical Infectious Diseases, ciw232.

24. O'Brien D, Tobin S, Brown GV, Torresi J. Fever in returned travelers: Review of hospital admissions for a 3-year period. Clin Infect Dis 2001;33(5):603-9.

25. Jelinek T, Nothdurft HD, von Sonnenburg F, Löscher T. Risk factors for typhoid fever in travelers. J Travel Med 1996;3:200-203.

26. Cammie FL, Miller SL. Salmonellosis. In: Kasper DL, Braunwald E, Fauci AS, Hauser SL, Longo DL, Jameson JL, editors. Harrison's Principles of Internal Medicine. New York: McGraw-Hill, 2005. p. 897-900

27. Bhutta ZA, Mansurali N. Rapid serologic diagnosis of pediatric typhoid fever in an endemic area: A prospective comparative evaluation of two dot-enzyme immunoassays and the widal test. Am J Trop Med Hyg 1999;61:654-7.

28. Ali AM, Gandhi V, Malla S. (2014). Development of multiplex pcr based assay for the concurrent detection of pathogenic microorganisms. International Journal of Current Pharmaceutical Research, 6(4), 25-27.

29. Rabie Zahran. Typhoid Fever. Available from: http://www.slideshare. net/rabiezahran/typhoid-fever-3610355. [Accessed on 2016 Aug, 31].

30. Hamer DH, Connor BA. Travel health knowledge, attitudes and practices among United States travelers. Journal of travel medicine. 2004;11(1):23-26.

31. Whitaker JA, Franco-Paredes C, del Rio C, Edupuganti S. Rethinking typhoid fever vaccines: Implications for travelers and people living in highly endemic areas. J Travel Med 2009;16(1):46-52.

32. Mirza SH, Beeching NJ, Hart CA. Multi-drug resistant typhoid: A global problem. J Med Microbiol 1996;44(5):317-9.

33. Gupta A. Multidrug-resistant typhoid fever in children: Epidemiology and therapeutic approach. Pediatr Infect Dis J 1994;13(2):134-40.

34. Mermin JH, Villar R, Carpenter J, Roberts L, Samaridden A Gasanova L, et al. A massive epidemic of multidrug-resistant typhoid fever in Tajikistan associated with consumption of municipal water. J Infect Dis 1999;179(6):1416-22.

35. Alam MN, Haq SA, Das KK, Baral PK, Mazid MN, Siddique RU, et al. Efficacy of ciprofloxacin in enteric fever: Comparison of treatment duration in sensitive and multidrug-resistant Salmonella. Am J Trop Med Hyg 1995;53(3):306-11.

36. Frenck RW Jr, Nakhla I, Sultan Y, Bassily SB, Girgis YF, David J, et al. Azithromycin versus ceftriaxone for the treatment of uncomplicated typhoid fever in children. Clin Infect Dis 2000;31(5):1134-8.

37. Effa EE, Bukirwa H. Azithromycin for treating uncomplicated typhoid and paratyphoid fever (enteric fever). Cochrane Database Syst Rev 2008;CD006083.

38. Nath G, Maurya P. Drug resistance patterns in Salmonella enterica subspecies enterica serotype typhi strains isolated over a period of two decades, with special reference to ciprofloxacin and ceftriaxone. Int J Antimicrob Agents 2010;35(5):482-5.

39. Stubi CL, Landry PR, Pétignat C, Bille J, Genton B, Darioli R, et al. Compliance to live oral Ty21a typhoid vaccine, and its effect on viability. J Travel Med 2000;7(3):133-7.

40. Eff ARY, Rahayu ST. (2016). The antibacterial effects of essential oil from galangal rhizome alpinia galanga (Linn.) Pierre ON RAT (Rattus norvegicus L.) were infected by Salmonella typhi. Asian Journal of Pharmaceutical and Clinical Research, 189-193.

41. Krishna, G., Kumar, S., Pranitha, V., Alha, M., \& Charaya, S. (2015). Biogenic synthesis of silver nanoparticles and their synergistic effect with antibiotics: A study against salmonella SP. International journa of pharmacy and pharmaceutical Sciences, 7(11), 84-88. Retrieved from http://innovareacademics.in/journals/index.php/ijpps/article/ view/7594.

42. Kanta Kanthal L, Dey A, Satyavathi K, Bhojaraju, P. (2014). Antibacterial potential of methanolic extract of gyrocarpus asiaticus willd. Asian Journal of Pharmaceutical and Clinical Research, 7(1), 192-194.

43. Mehta J, Jandaik SU. (2016). Evaluation of Phytochemicals and synergistic interaction between plant extracts and antibiotics for efflux pump inhibitory activity against salmonella typhimurium strains. International Journal of Pharmacy and Pharmaceutical Sciences, 8(10) Retrieved fromhttp://innovareacademics.in/journals/index.php/ijpps article/view/14062. 